\title{
Cyclamen europaeum nasal spray, a novel phytotherapeutic product for the management of acute rhinosinusitis: a randomized double-blind, placebo-controlled trial*
}

\author{
O. Pfaar 1,2, J. Mullol' ${ }^{3}$, C. Anders' ${ }^{1}$, K. Hörmann', L. Klimek² \\ Department of Otorhinolaryngology, Head and Neck Surgery, University Hospital Mannheim, Germany \\ Center for Rhinology and Allergology, Wiesbaden, Germany \\ 3 Unitat de Rinologia \& Clínica de I'Olfacte, Department of Otorhinolaryngology, Hospital Clínic-IDIBAPS, CIBERES. Barcelona, \\ Catalunya, Spain
}

Rhinology 50: 37-44, 2012 DOI: $10.4193 /$ Rhino 11.141 *Received for publication: April 24, 2011

accepted: September 12, 2011

\section{Summary}

Aim: To evaluate the efficacy and safety of a phytotherapeutic nasal spray containing Cyclamen europaeum (CE) in the treatment of acute rhinosinusitis (ARS).

Material/Methods: We performed a randomized, double-blind, placebo-controlled trial of CE nasal spray once daily for 15 days in 99 adult patients with moderate-to-severe ARS who also received amoxicillin $500 \mathrm{mg}$ three times daily for the first 8 days. The primary endpoint was the change in mean total symptom scores (TSS) on day 7. Secondary endpoints included individual symptom scores (nasal congestion, mucus secretion, facial pain, impairment of smell) and endoscopic findings on days 7 and 15 and others.

Results: No statistically significant difference in TSS was noted for CE versus placebo on day 7. Moreover, the individual scores were not statistically different between the groups for the ITT-population on day 7. However, both a reduction in facial pain (PP) and an improvement in endoscopically-assessed mucosal obstruction (ITT) significantly favoured CE on day 7. The most common adverse events were nasal burning and mild epistaxis, but no severe adverse events were documented.

Conclusion: In summary, this is the first randomized controlled trial on phytotherapy in patients with moderate-to-severe ARS demonstrating clinical safety and some encouraging effects of $C E$ which merit to investigate phytotherapeutic products in further large-scale clinical trials.

Key words: Cyclamen europaeum, acute rhinosinusitis, $\mathrm{EP}^{3} \mathrm{OS}$, phytotherapy

\section{Introduction}

Rhinosinusitis is a common upper respiratory tract disorder caused by inflammation of the nose and paranasal sinuses which affects up to $16 \%$ of the general population ${ }^{(1-3)}$. Patients report a variety of symptoms, often including nasal discharge, nasal congestion or blockage, facial pressure or pain, a reduced sense of smell, headache, and fever ${ }^{(2,4)}$. It can present as acute rhinosinusitis (ARS) with symptoms lasting less than 12 weeks or as chronic rhinosinusitis (CRS) with symptoms persisting for more than 12 weeks ${ }^{(4)}$. Both ARS and CRS affect the quality of life of individuals and increase the healthcare system resources and costs ${ }^{(1,4-9)}$.

ARS is an acute inflammatory disease of the nasal and sinusal mucosa with the initial presentation invariably being viral (common cold), although bacterial superinfection can occur and this represents a more serious clinical challenge ${ }^{(4,5)}$. Undoubtedly, there is a high prevalence of mild ARS from viral origin (common cold). According to the European Position Paper on Rhinosinusitis and Nasal Polyps 2007 (EP3OS 2007), schoolchildren may experience 7 - 10 colds per year and adults 2 - 5 per year (4). As might be expected, exact prevalence rates are difficult to 
ascertain since most affected individuals do not consult their physician. Bacterial ARS is not as common. However, over 6 million cases are noted in Germany per year and over 20 million in the USA ${ }^{(7,10)}$. This disease is the fifth most frequent reason for prescribing antibiotics in the USA, which represents more than $20 \%$ of all prescriptions filled for adults in need of antibiotic therapy ${ }^{(7)}$.

The central pathophysiologic process in rhinosinusitis is inflammation of the nasal and paranasal passages ${ }^{(2,4)}$. This results in oedema and excess mucus secretion within the epithelial tissues, leading to obstruction of the sinuses, impaired ciliary function and reduced mucus transportation.

The aim of sufficient therapy is to control symptoms, to ameliorate the quality of life of patients and, moreover, to prevent progression or recurrence of the disease ${ }^{(2-4,9)}$. EP $\mathrm{P}^{3} \mathrm{OS}$ proposed evidence based guidelines for the diagnosis and treatment of rhinosinusitis which were suitable for use by both primary- and secondary-care clinicians ${ }^{(4)}$. For the treatment of ARS both oral antibiotics and topical corticosteroids, either as monotherapy or in combination, were given a grade-A recommendation with evidence-levels of la and Ib, respectively.

To date, the lack of published randomized, double-blind, placebo-controlled studies has resulted in a low level of clinical evidence for phytotherapy in the treatment of ARS and, consequently, it is not currently recommended in the $\mathrm{EP}^{3} \mathrm{OS}$ guidelines ${ }^{(4)}$. Cyclamen europaeum (hereafter referred to as $C E$ ) has been shown to reduce mucosal oedema, improve ciliary activity, and enhance drainage and ventilation of the sinuses in first clinical trials ${ }^{(11-13)}$. Therefore, the aim of this multicenter, placebocontrolled study was to evaluate the clinical efficacy and safety of CE nasal spray in patients with moderate to severe ARS who were also receiving antibacterial therapy.

\section{Materials and methods}

Patients

Adult men and women aged 18 - 65 years with moderate to severe ARS according to the criteria of the first European Position Paper on Rhinosinusitis and Nasal Polyps ${ }^{(14)}$ were eligible for enrolment. Patients had inflammation of the nasal and paranasal sinuses lasting $>10$ days (amended shortly after study commencement with symptoms lasting more than 7 days) and $<12$ weeks with at least two of the following symptoms: nasal obstruction, anterior or posterior nasal secretion, facial pain/ tension/ pressure, and/ or impaired or loss of the sense of smell. In addition, patients could have mucopurulent secretion in the middle meatus, and mucus oedema or nasal obstruction predominantly in the middle meatus, on nasal endoscopy.

Intensity of rhinosinusitis symptoms was assessed using a visual analogue scale $(0-10 \mathrm{~cm})$. 'Moderate-to-severe' intensity was understood when the patient answered the question 'How troublesome are your rhinosinusitis symptoms?' with a vertical line on a visual analogue scale (VAS) from $0=$ 'not troublesome' to 10 = 'unbearably bothersome', and this line was between 5 and $10^{(14)}$.

Exclusion criteria included CRS and nasal polyposis, severe mechanical nasal obstruction, severe asthmatic patients, intolerance to acetyl salicylic acid, treatment with anticoagulants or anticholinergic (antimuscarinic or direct parasympatholytic) drugs, treatment with topical nasal corticosteroids within 72 hours of study start or with an antibacterial agent within 48 hours (amended shortly after study commencement to exclude antibacterial treatment associated with symptom improvement within 72 hours).

\section{Study design}

This randomized, double-blind, placebo-controlled trial was performed at 13 centres in Germany. It was conducted in ac cordance with the World Medical Association Declaration of Helsinki and the International Conference on Harmonization (ICH) Harmonized Tripartite Guidelines for Good Clinical Practice. The institutional review board for each site approved the protocol and patients provided written informed consent prior to their inclusion into the study.

After confirmation of eligibility and completion of baseline assessments, patients were randomly assigned to treatment with either CE nasal spray (herbal lyophilised extract) or matching placebo nasal spray for 15 days. One spray of $1.3 \mathrm{mg}(0.13 \mathrm{~mL})$ was administered into each nostril once daily in the evening. In addition, all patients received amoxicillin $500 \mathrm{mg}$ three times daily for the first 8 days (or a suitable alternative at the discretion of the physician for those allergic to penicillin). Concomitant treatment with corticosteroids or decongestants was not allowed during the study.

\section{Clinical assessments}

Prior to treatment, patients provided a medical history and underwent a physical examination, including nasal endoscopy. During the study patients completed symptom diaries, and at the end of the study patients and investigators made an overall assessment of treatment satisfaction. Rhinosinusitis symptoms, including i) nasal obstruction ii) (anterior or posterior) mucus secretion, iii) facial pressure/pain, and iv) impairment or loss of smell, were assessed using visual analogue scales (VAS: 0 to 10 $\mathrm{cm}$; from $0=$ absent to $10=$ maximum intensity).

Four-point Likert scales were used for endoscopic findings, with mucopurulent secretion in the middle meatus scored from $0=$ none to $3=$ profuse, and mucus oedema or nasal obstruction (predominantly in the middle meatus) scored from $0=$ no oedema or obstruction to $3=$ oedema with severe 
obstruction.

Sleep quality was assessed using a visual analogue scale (0 - 10 $\mathrm{cm}$; where $0=$ slept well and $10=$ slept badly) .

The primary efficacy variable was the change from baseline in the mean total rhinosinusitis symptom score after 5 - 7 days (averaged from patient assessment of nasal obstruction, mucus secretion, facial pressure/pain, and impairment or loss of smell). Secondary efficacy variables included change from baseline in the four individual nasal symptoms at 5 - 7 days, changes in total symptom scores and in the four individual nasal symptoms at 15 days, endoscopic signs at $5-7$ and 15 days, treatment failure/ need for additional treatment, onset of medical complications of rhinosinusitis, sleep quality, and overall patient- and investigator-assessed treatment satisfaction.

\section{Safety}

Adverse events were monitored throughout the study, as was the development of any medical complication associated with progression of rhinosinusitis (for example, orbital, endocranial or bone complications).

\section{Statistical methods}

Prior to the study, a power-calculation was performed. It was determined that 45 patients per group would be required to detect a difference of 3 points between means for the primary endpoint, with a power of $80 \%$ and assuming a standard deviation of 5 points. Allowing for $10 \%$ loss, it was planned to enrol 100 patients.

The primary efficacy analysis was performed using the intentionto-treat population (ITT; all randomised patients). Where day 5-7 data were not available, a last observation point carried forward (LOCF) methodology was employed. The primary endpoint was evaluated using analysis of covariance (ANCOVA) with the centre, treatment group and baseline value as adjustment variables. Data from centres that enrolled $<3$ patients per group were aggregated. The effect of treatment (difference between the adjusted means) was estimated using $95 \%$ confidence intervals (CI). Secondary endpoints were evaluated using ANCOVA or t-test (continuous variables) or the Cochrane-Mantel-Haenzel test (categorical variables). A per-protocol (PP) analysis was also performed which comprised the ITT population, but who had no major protocol violations and could be evaluated for the primary endpoint. The safety analysis population included all randomized patients who received at least one dose of study medication.

\section{Results}

A total of 99 patients with ARS were randomized (48 in the CE group and 51 in the placebo group). Patient numbers (ITT-population, reason for withdrawal and PP-population) are shown in Figure 1. Baseline demographic characteristics were comparable for the two groups (Table 1).

Patients in both groups reported moderate-to-severe symptoms with mean total symptom scores of 6.2 in the CE group and 5.7 in placebo group (the difference was not statistically significant). A prior history of various respiratory disorders was common (181 reports in the overall study population).

\section{Efficacy}

In the primary efficacy analysis (change in mean rhinosinusitis total symptom VAS score after 5-7 days for the ITT population) there was a trend towards greater symptomatic relief with CE -2.7 (95\% Cl-3.4 to -2.1) compared with placebo -2.5 (95\% Cl -3.1 to -2.0$)$ that did not achieve statistical significance $(p=0.64)$. An analysis of secondary efficacy outcomes also demonstrated

Table 1. Demographic characteristics of study population at baseline.

Gender [number]

\begin{tabular}{|c|c|c|}
\hline Male & $16(33.3)$ & $19(37.2)$ \\
\hline Female & 32 (66.6) & $32(62.7)$ \\
\hline \multicolumn{3}{|l|}{ Age (years) (\%) } \\
\hline Mean (SD) & $40.0(13.0)$ & $39.3(11.4)$ \\
\hline Range (min-max) & $19-65$ & $18-64$ \\
\hline \multicolumn{3}{|l|}{ Race [number (\%)] } \\
\hline Caucasian & $47(97.9)$ & $50(98.0)$ \\
\hline Other & $1(2.0)$ & $1(1.9)$ \\
\hline $\begin{array}{l}\text { Total rhinosinusitis symptom score at baseline }( \pm S D) \text { from averaged VAS } \\
\text { scores }[0=\text { none and } 10=\text { maximum severity }]\end{array}$ & $6.2(1.9)$ & $5.7(1.9)$ \\
\hline
\end{tabular}

VAS = visual analogue scale 
Table 2. Effect of Cyclamen europaeum on individual rhinosinusitis symptoms and endoscopic signs (ITT population).

\begin{tabular}{|c|c|c|c|c|c|c|}
\hline & \multicolumn{4}{|c|}{$\begin{array}{l}\text { Symptoms } s^{\mathrm{a}} \text { - mean change from baseline } \\
\text { [based on a VAS scores }(0-10)]\end{array}$} & \multicolumn{2}{|c|}{$\begin{array}{c}\text { Endoscopy } y^{b} \text { mean change from } \\
\text { baseline }\end{array}$} \\
\hline & $\begin{array}{l}\text { Nasal } \\
\text { obstruction }\end{array}$ & Mucus secretion & $\begin{array}{l}\text { Facial pain/ } \\
\text { pressure }\end{array}$ & $\begin{array}{l}\text { Impairment/loss } \\
\text { of smell }\end{array}$ & $\begin{array}{l}\text { Mucosal } \\
\text { oedema/Nasal } \\
\text { obstruction }\end{array}$ & $\begin{array}{l}\text { Mucopurulent } \\
\text { secretion }\end{array}$ \\
\hline \multicolumn{7}{|l|}{ Day 5-7 } \\
\hline Cyclamen & -3.46 & -2.61 & -4.28 & -2.60 & $-2.5^{*}$ & -1.8 \\
\hline Placebo & -2.87 & -2.26 & -3.39 & -2.12 & -1.8 & -1.6 \\
\hline \multicolumn{7}{|l|}{ Day $12-15$} \\
\hline Cyclamen & -4.99 & -3.90 & -5.57 & -3.72 & -3.7 & -3.2 \\
\hline Placebo & -4.69 & -3.78 & -4.79 & -3.54 & -3.1 & -3.0 \\
\hline
\end{tabular}

VAS $=$ visual analogue scale; ${ }^{*} p<0.03$ vs placebo

a greater decrease in mean symptom scores (nasal congestion, mucus secretion, facial pain, and impairment or loss of smell) in the CE group for the ITT-population without significant differences to placebo (Table 2). However, after 5 - 7 days a reduction in facial pain significantly favoured CE (between group difference of -1.20 [95\% Cl -2.32 to $-0.08 ; p<0.04]$ ) for the PP-population (Figure 2A).

Endoscopic evaluation demonstrated that mucus oedema or nasal obstruction was reduced to a significantly greater extent with $C E$ than placebo after 5-7 days, with an adjusted mean difference in score of -0.76 points $(95 \% \mathrm{Cl}-1.44$ to $-0.08 ; \mathrm{p}<0.03$; ITT population; Figure 2B). There were no significant betweengroup differences for mucopurulent secretion in the middle meatus at either timepoint.

A post hoc analysis of endoscopic improvement (defined as a sum of endoscopy scores of 0 ) found significant differences between active and placebo-treated groups in per-protocol analysis, as the rate of improvement was significantly higher with $C E$ than placebo after $12-15$ days (48.7\% vs $30.9 \%$; $p<0.05)$.

No patients needed additional treatment for rhinosinusitis during the study, and there were no medical complications associated with progression of ARS. There were no differences between groups for change in sleep quality (mean sleep quality scores for the $C E$ and placebo groups were $3.9 \pm 2.3$ vs. $3.4 \pm$ 2.0 after $5-7$ days and $1.9 \pm 1.8$ vs. $2.0 \pm 1.9$ after $12-15$ days, respectively.

At the end of the study, mean patient- and investigator-rated satisfaction scores were statistically significantly improved in the CE group compared with placebo (Figure 3, ITT-population).

\section{Safety}

Adverse events were reported by $67 \%$ of the CE group and $29 \%$ of placebo recipients. Transient mild to moderate nasal irritation/burning occurred in both treatment groups, but was more frequent with CE (50\% vs. 4\%). The only other effects, which occurred on more than one occasion, were mild epistaxis (27\% in the CE group compared to $14 \%$ in the placebo group) and vertigo (4\%) in the placebo group. Sneezing was reported by 2 patients in the CE group. Almost all adverse events resolved without intervention. However, study medication was permanently discontinued in 3 patients in the $C E$ group and 2 in the placebo group because of adverse effects (Figure 1). No severe adverse events were reported.

\section{Discussion}

To our knowledge, this is the first randomized, double-blind, placebo-controlled clinical trial evaluating the efficacy and safety of a phytotherapeutic medication (extract of Cyclamen europaeum), administered in conjunction with an antibacterial agent, in the treatment of moderate to severe ARS.

Rhinosinusitis is one of the most frequent upper respiratory diseases which are treated in the physician's normal practice routine ${ }^{(7,15)}$. The condition has an adverse effect on general mental and physical health ${ }^{(16)}$ and is associated with a heavy economic burden, which includes reduced productivity and absenteeism, as well as the medical costs associated with treatment ${ }^{(1,4,17)}$. ARS, which can be viral or bacterial in origin, is a particularly common presentation in general practice and represents an important charge on healthcare resources (see introduction). Because of difficulties in differentiating between viral and bacterial disease, physicians frequently resort, often inappropriately, to prescribing antibiotics. As noted earlier, the fifth most frequent reason for antibiotic treatment in US-American adults is due to ARS (7). 


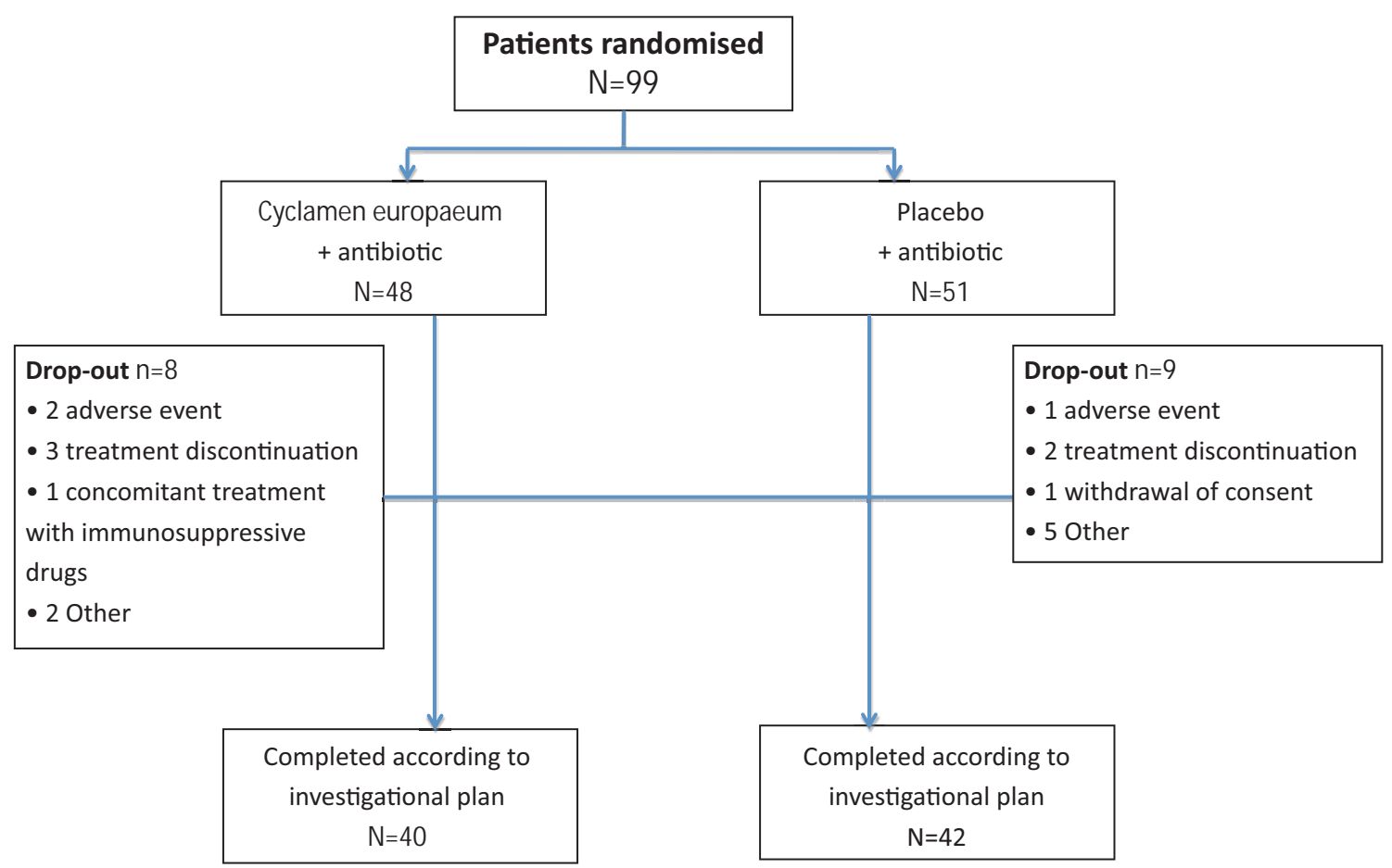

Figure 1. Study flowchart.

The inflammation of the nasal and paranasal passages that occurs in rhinosinusitis is often associated with mucociliary impairment, infection or allergy ${ }^{(9)}$. A number of treatment options are available, including topical corticosteroids, antimicrobial agents, decongestants, antihistamines, analgesics, mucolytics and saline nasal douching ${ }^{(4)}$. Of these, major guidelines recommend the use of oral antibiotics agents and nasal corticosteroids, with the former generally reserved for patients who have severe (bacterial) disease (patients with fever higher than $38^{\circ} \mathrm{C}$ and/or severe unilateral facial pain), and nasal corticosteroids recommended in both moderate (monotherapy) and severe (combined with oral antibiotics) disease ${ }^{(3,4)}$. Some guidelines also recommend using antihistamines, if the patient suffers from allergic rhinitis ${ }^{(3,4)}$, saline douching ${ }^{(3)}$, or decongestants for symptom relief ${ }^{(4)}$. In the primary care setting, the majority of patients are prescribed an antibacterial agent, despite the fact that most uncomplicated cases are viral, or at least non-bacterial ${ }^{(18,19)}$. Antibacterial drugs are most likely to be of benefit in patients with a proven bacterial infection, those with signs of a serious infection, or those who are at high risk of complication (immunocompromised patients).

Since inflammation is responsible for several of the key symptoms of ARS, such as nasal congestion, nasal obstruction and facial pain, agents that reduce inflammation and improve drainage from the sinuses can help provide symptom relief ${ }^{(2)}$. Topical decongestants reduce nasal congestion, but can be associated with rebound congestion if administered for longer than a few days ${ }^{(2,4)}$. Intranasal corticosteroids have been shown to be of benefit in the treatment of ARS ${ }^{(2,4)}$. Most studies evaluated the use of corticosteroids in combination with antibacterial agents, although one study showed that monotherapy was effective in patients at low risk of bacterial infection ${ }^{(20)}$. In a recent meta-analysis of intranasal corticosteroids in ARS, modest benefit was reported in 4 studies involving a total of 1943 patients. Higher doses produced greater improvement in symptoms and, overall, intranasal treatment was well-tolerated ${ }^{(21)}$.

To date, there appears to be no substantive evidence regarding the role of phytotherapy in the treatment of ARS. In the current $E P^{3} \mathrm{OS}$ guidelines the use of phytotherapy in ARS considered not relevant, with evidence level lb (negative) and grade of recommendation $D^{(4)}$. Results from a number of small uncontrolled studies in Eastern Europe provided some encouraging results following topical administration of $C E$ nasal spray ${ }^{(11,12)}$. Recently, a placebo controlled, randomised study performed in the USA provided initial evidence that 7 days' monotherapy with $C E$ nasal spray reduced sinus occlusion (assessed using CT scans) in patients with moderate to severe ARS ${ }^{(13)}$.

In our study, patients received CE for 15 days, together with an antibacterial agent for the first 8 days. Although differences in total symptom relief did not reach statistical significance in the main analysis, there appeared to be a tendency for individual symptoms to improve with $C E$ during the first week of treatment, and the specific symptom of facial pain/pressure 
(A)

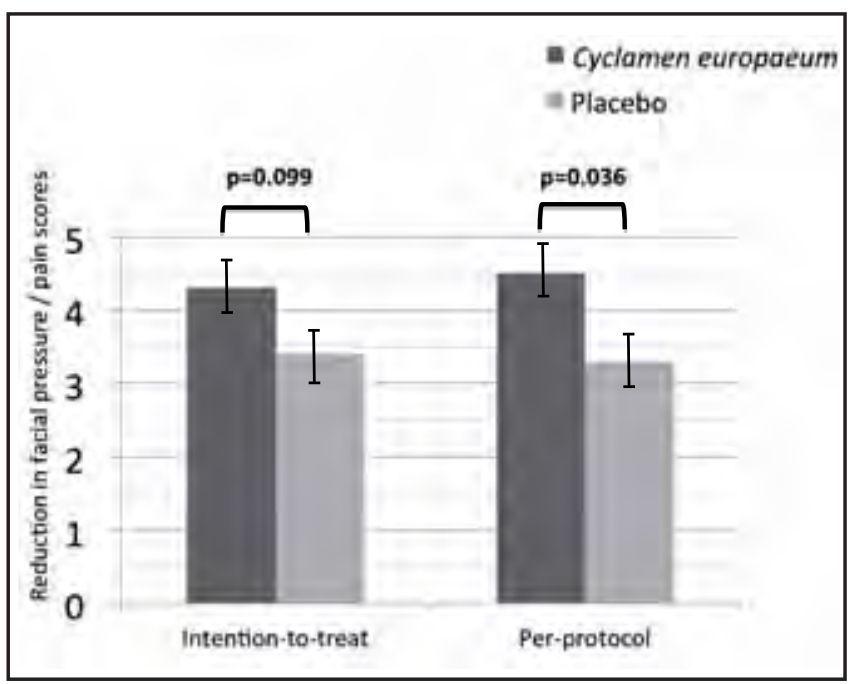

(B)

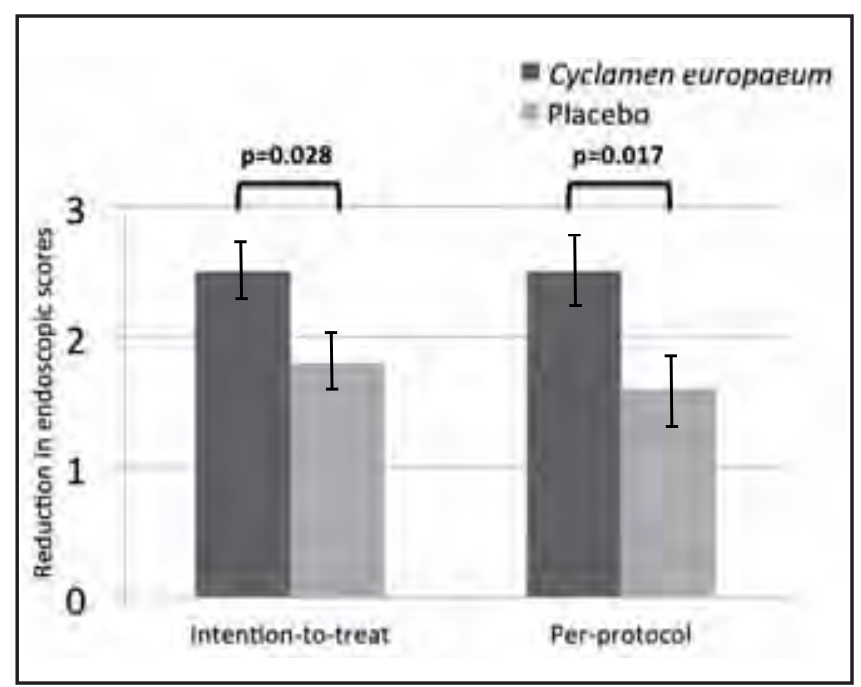

Figure 2. Reduction in (A) mean facial pressure/pain-score at day 5-7 in ITT- and PP-populations [change assessed using visual analogue scales, where $0=$ symptom absent and $10=$ maximum severity] and (B) 5-7 days endoscopic scores for nasal obstruction/mucus oedema in patients treated with Cyclamen or placebo.

did improve significantly after 5 - 7 days treatment with CE in the per-protocol analysis. This is important since facial pain/ pressure is undoubtedly one of the most severe symptoms affecting the patients' quality of life in ARS $(4,22)$. Endoscopic evaluation was used to assess the effect of treatment on objective signs of rhinosinusitis such as mucus oedema and mucopurulent secretions within the middle meatus. Mucus oedema/nasal obstruction improved significantly with CE during the first week in both the ITT and per-protocol analyses. In addition, the per-protocol analysis showed that endoscopic improvement (defined as a sum of endoscopy scores of 0) was significantly higher with $C E$ than placebo at the end of the study. In addition to the clinical scores discussed above, these endoscopic differences reaffirm the clinical efficacy of $C E$ nasal spray in adult patients with ARS.

The results relating to symptomatic relief are reflected in the findings that both patients and investigators reported significantly greater treatment satisfaction with $C E$ than placebo. More than two-thirds of patients treated with CE were very, or quite, satisfied with treatment compared with just under half of placebo recipients.

Adverse events reported for $C E$ during the study tended to be mild. No unexpected events occurred, and most were consistent with the mechanism of action of CE or with ARS per se. In line with the local action of $C E$ in the nasal sinuses, a temporary burning sensation or sneezing can occur after application. In the current study, mild to moderate nasal burning/irritation was the most common adverse event reported, occurring in half of the patients treated with CE. However, it should be noted that this adverse effect might influence the doubleblinding of the study since both patients and their physicians may link this to active therapy.

In conclusion, CE nasal spray represents a novel phytotherapeutic approach for the treatment of symptoms associated with ARS. In this well-controlled randomized clinical trial $C E$-treatment was safe and associated with some encouraging clinical effects. Even though a statistical significant change in total symptom rhinosinusitis scores as primary endpoint was not demonstrated these findings merit further assessment of phytotherapeutic nasal sprays in a larger cohort of patients with acute or chronic rhinosinusitis, as it remains a common and highly symptomatic disorder despite a wide array of treatment options.

\section{Conflict of interest statement}

O. Pfaar and L. Klimek have received research grants and/or have served as advisors and on the speaker's bureau for the following companies: ALK Abello, Denmark; Allergopharma, Germany; Glaxo-Smith-Kline, U.K.; Stallergenes, France; HAL, Netherlands; Artu Biologicals, Netherlands; Allergy Therapeutics/Bencard, U.K./Germany; Hartington, Spain; Lofarma, Italy; Novartis/Leti, Germany/Spain; Roxall,Germany; Essex, Germany.

J Mullol has been member of National/International Scientific Advisory Boards for UCB Pharchim, Grupo Uriach SA, Schering Plough, GSK, Hartington Pharmaceuticals, MSD, and FAES; received grants for research projects from Schering-Plough, 


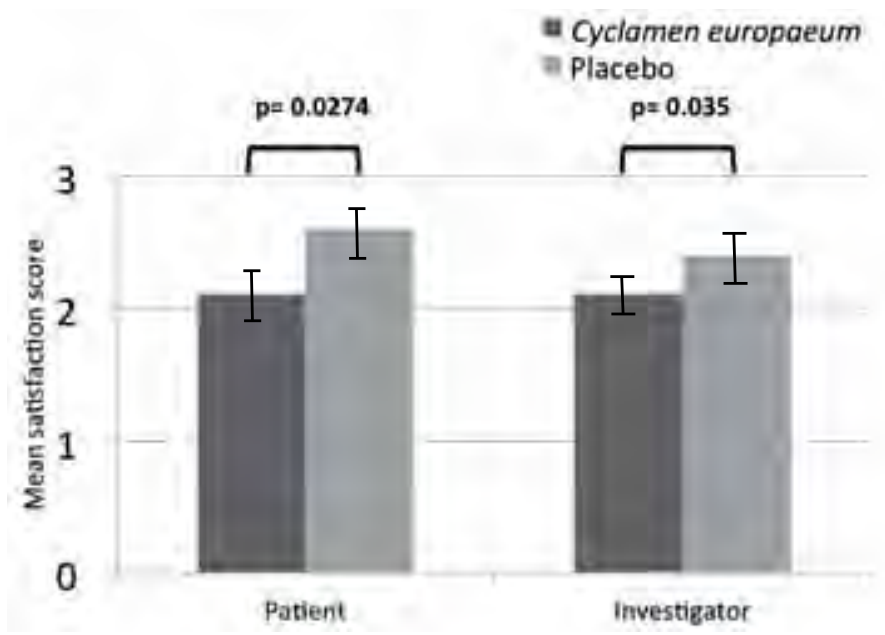

Figure 3. Mean patient and investigator satisfaction scores in patients treated with Cyclamen or placebo for 12-15 days (scores based upon a 5 point scale where $0=$ completely satisfied and $5=$ completely dissatisfied).

Grupo Uriach SA, UCB Pharchim, and MSD; and has been main investigator and/or national/international coordinator of clinical trials for UCB Farma, FAES, Grupo Uriach SA, GSK, and Schering-Plough.

\section{Acknowledgements}

This clinical trial was supported by a financial grant from
Hartington Pharmaceutical, Spain. We thank the following investigators for participating in this study: H. Müller, Leipzig; R.W. Blasius, Halle; J. Heine, Gütersloh; K. Krekeler, Bad Oeynhausen; J. Landwehr, Bielefeld; H. Meuser, Holte-Stukenbrock; F.G. Drees, Bielefeld; E. Seeger-Schellerhoff, Porta Westfalica / Barkhausen; C. Taut, Ganderkesee; H. Kyrberg, Ludwigshafen; R. Eichler, Mannheim.

\section{References}

1. Anand VK. Epidemiology and economic impact of rhinosinusitis. Ann Otol Rhinol Laryngol Suppl. May 2004; 193: 3-5.

2. Lund VJ. Therapeutic targets in rhinosinusitis: infection or inflammation? Medscape J Med. 2008; 10: 105.

3. Scadding GK, Durham SR, Mirakian R, et al. $\mathrm{BSACl}$ guidelines for the management of rhinosinusitis and nasal polyposis. Clin Exp Allergy. 2008; 38: 260-275.

4. Fokkens W, Lund V, Mullol J. EP3OS 2007: European position paper on rhinosinusitis and nasal polyps 2007. A summary for otorhinolaryngologists. Rhinology. 2007; 45: 97-101.

5. Meltzer EO, Hamilos DL, Hadley JA, et al. Rhinosinusitis: establishing definitions for clinical research and patient care. J Allergy Clin Immunol. 2004; 114(6 Suppl): 155-212.

6. Klossek JM, Federspil P. Update on treatment guidelines for acute bacterial sinusitis. Int J Clin Pract. 2005; 59: 230-238.

7. Marple BF, Brunton S, Ferguson BJ. Acute bacterial rhinosinusitis: a review of U.S. treatment guidelines. Otolaryngol Head Neck
Surg. 2006: 135: 341-348.

8. Bhattacharyya N. Contemporary assessment of the disease burden of sinusitis. Am J Rhinol Allergy. 2009; 23: 392-395.

9. Dykewicz MS, Hamilos DL. Rhinitis and sinusitis. J Allergy Clin Immunol. 2010; $125(2$ Suppl 2): S103-115.

10. Bachert C, Hormann K, Mosges R, et al. An update on the diagnosis and treatment of sinusitis and nasal polyposis. Allergy. 2003; 58: 176-191.

11. Rybak AA, Matveeva TV, Nepri VG. Effects of sinuforte on quality of life in rhinosinusitis patients. Vestn Otorhinolaringol. 2008: 56-58.

12. Gedevanishvili MD, Gogitidze NM, Sikharulidze IS. Reflex mechanisms of nasoparanasal secretion in the administration of Sinuforte. Vestn Otorhinolaringol. 2007; 3 .

13. J.U. Ponikau, J.U. Hamilos, D.L. Barreto, A. Cecil, J, Jones S.W., Manthei SE. Efficacy and Safety of Cyclamen europaeum extract nasal spray in acute sinusitis: a randomized clinical trial. 1st Congress of CEORL-HNS; 2011; Barcelona. Poster 2170
14. Fokkens W, Lund V, Bachert C, et al. EAACl position paper on rhinosinusitis and nasal polyps executive summary. Allergy. 2005; 60: 583-601

15. Schappert SM, Burt CW. Ambulatory care visits to physician offices, hospital outpatient departments, and emergency departments: United States, 2001-02. Vital Health Stat 13. 2006: 1-66.

16. Macdonald KI, McNally JD, Massoud E. The health and resource utilization of Canadians with chronic rhinosinusitis. Laryngoscope. 2009: 119: 184-189.

17. Watelet JB, Eloy PH, van Cauwenberge PB. Drug management in chronic rhinosinusitis: identification of the needs. Ther Clin Risk Manag. 2007; 3: 47-57.

18. Ashworth M, Charlton J, Ballard K, Latinovic $\mathrm{R}$, Gulliford M. Variations in antibiotic prescribing and consultation rates for acute respiratory infection in UK general practices 1995-2000. Br J Gen Pract. 2005; 55: 603-608.

19. Small CB, Bachert C, Lund VJ, Moscatello A, Nayak AS, Berger WE. Judicious antibiotic use and intranasal corticosteroids in acute rhinosinusitis. Am J Med. 2007; 120: 289-294. 
20. Meltzer EO, Bachert C, Staudinger H.

Treating acute rhinosinusitis: comparing

efficacy and safety of mometasone furo-

ate nasal spray, amoxicillin, and placebo. J

Allergy Clin Immunol. 2005; 116: 1289-1295.

21. Zalmanovici A, Yaphe J. Steroids for acute

sinusitis. Cochrane Database Syst Rev. 2007:

CD005149. Update in: Cochrane Database
Syst Rev. 2009; 4: CD005149.

22. Williams JW, Jr., Simel DL. Does this patient have sinusitis? Diagnosing acute sinusitis by history and physical examination. JAMA. 1993: 270: 1242-1246
Priv.-Doz. Dr. Oliver Pfaar, M.D. Center for Rhinology and Allergology Dept. of Otorhinolaryngology, Head and Neck Surgery

University Hospital Mannheim An den Quellen 10 D-65183 Wiesbaden Germany

Tel: +49-611-308-608 0

Fax: +49-611-308-608 255

E-mail:

oliver.pfaar@allergiezentrum.org

\title{
$15^{\text {th }}$ CIRAS
}

(Croatian International Rhinosurgical Advanced School)

\author{
Zagreb, Croatia
}

October 9-12, 2012

\section{UNDER THE AUSPICES OF ERS}

Four day intensive course on functional endoscopic nose and sinus surgery \&

functional and aesthetic surgery of the nose

Teachers Board:

Apaydin (Turkey), Bellussi (Italy), Castelnuovo (Italy), Cingi (Turkey), Eloy (Belgium), Hellings (Belgium), Jurlina (Croatia), Kawauchi (Japan), Kennedy (USA), Kozlov (Russia), Ku (Hong Kong), Lopatin (Russia), Manea (Romania), Marjanović (Croatia), Mladina (Croatia), Nolst Trenite (The Netherlands), Passali (Italy), Poje (Croatia),

Prstačić (Croatia), Sarafoloeanu (Romania), So (Hong Kong), Sousa Vieira (Portugal), Stierna (Sweden), Wong (Hong Kong), Vuković (Croatia)

Twice a day live surgery, every day attractive animal model dissections (Karl Storz manual and DVD), 58 lectures, UEMS - EACCME accreditation points, number of participants strictly limited to 70 (numerus clausus)

Early registration highly recommended (www.ciras.eu) 